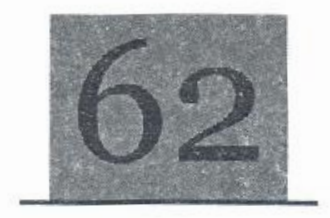

\title{
Growth pattern and specificity of attachment of lagoon crab (Callinectes amnicola) fouled with barnacles (Chelonibia patula) from Lagos Lagoon, Southwest Nigeria
}

\author{
Lawal-Are, A. O./ Akinwunmi, M. F. / Afolabi, J. O.
}

\begin{abstract}
The growih pattern and condition factor (K) of 810 Lagoon crabs (Callinestes amnicola) fouled with Barnacles (Chelonibia paiula), collected from Makoko Jetty off Lagos Lagonn between April-ieptember. 2011 were studied. The carapace length of C. amnicola examined ranged from $3.8 \mathrm{~cm}-8.6 \mathrm{~cm}$ while the carapace width ranged from $9.5 \mathrm{~cm}-15.4 \mathrm{~cm}$. The total weight ranged from $53.1 \mathrm{~g} i 0165.0 \mathrm{~g}$, indicating that increase in length correspond to increase in weight, thereby suggested that C. amnicola from Lagos Lagonn exhibiled a negative aitometric growth. The correlated coefficient ' $r$ ' for the crahs was 0.68 , showing a law correlation between carapace length and total weight in the lagoon crabs fouled with barnacles. The condition factor $(K)$ values of $C$. amnicola fouled with barnacles ranged from 3.2-9.7 with a mean value of 5.4. The highest $K$-value was recorded for the size group 3.5-4.4. The valwe decreased with increase in carapace length of $\mathrm{C}$. umnicola. The sex ratio $(1: 80)$ indicated that there were more females $(98.8 \%)$ than males $(1.2 \%) .12(1.5 \%)$ out of the 810 lagoon crabs examined were heavily fouled with barnacles distributed all over the points of atlachment with the carapace having the most atiachment $(91.6 \%)$. Average diameter of the barnacles atiached to the crabs ranged from $0.23 \mathrm{~cm}$ io $1.85 \mathrm{~cm}$. The distribution shows that large-sized crabs had mich bamacles attached to them than small-sized crabs, with greats? barnacies found oniy in the females than in the males.
\end{abstract}

Keywords: Callinecte's amnicola, Chelonibia patuta, specificity, lagoon, condition factor; sex ratiu.

\section{Introduction}

rabs are economically important shell-fish that share the same phylum Arthropoda with other successful animals with exoskelewns such as insects and spiders with over 42,000 extant species. These crustaceans with broad, cornpact body and abdomen which is greatly reduced and tucked away underneath the cephalothorax (1lickman et al., 1996) are related to lobsters, shrimps and crayfish and belong to the same subphylum malacostraca with barnacles. Barnacles unlike crabs belong to the order Cirripedidid while crabs belong to order decapoda. The crabs are so numerous with many familics These can be grouped into two broad categories: infra order Brachyura (true crabs) and infra order Anomuran (false crabs) According $t o$ Schneider (1990). Brachyurans can be divided into the family Calappidae, Graspidae, Gecarcinidae, Geryonidae, Homolidae, Majidae, Ocypodidac, Ocypodidae, Xanthidae and Portunidae.

The Lagoon crabs, Callinectes amnicola which favour brackish bays, are the most edible crab along the coastal habitats in the temperate, subtropical and tropical regions (Carmona-Suarez and Conde, 1996). The blue crabs due to their euryhaline nature are more widely distributed in our water. According to Lawal-Are and Kusemiju, 2000; the Lagos Lagorn supports a major crab's fishery based on the abundance of the blue crab. The blue crabs, C: amnicola are mostly ormivores (Warner, 1982) and will eat any vegetable ot animal matter preferably freshly dead or freshly caught. They also will crush and eat young oysters or clams. According to Zimmer (2004), the most frequently noticed parasite of crabs is the rhizocephalan barnacle of the genus Sacculina. Crabs could also have a symbiotic association or commensalisms. Example of such relationship is the onc between crabs and barnacle, Chelonibia patula (William, 1984).

Barnacles and their larvae are distributed throughout the world because of their attachment to the bottoms of ships. They also use their calcareous plates $w$ attach solidly to floating timbers, large fish and shellfish. The unwanted colonization of a substrate in aquatic environments by a diversc array of organisms is known as "Biofouling" (Anderson et. al.; 2003). According to Panchal, (1984), biofouling is simply the attachnent of an organism or organisms to a surtace in contact with 
water for a period of time. The problem of biofouling is more serious in tropical waters. Cold waters have a low prevalence of biofouling, perhaps because of the physiology of the organisms responsible (Panchal, 1984). The most visible and prominent forms of fouling organisms as reported by Anderson et al. (2003) are barnacles, mussels, tubeworms, acsidians bryozoans and seaweed. The focus of this study is to study some aspects of biology of the lagoon crab, Callinectes amnicola and describe $\checkmark$ the distribution of the ectosymbiotic barnacle, Chelonibia patula on the host crab.

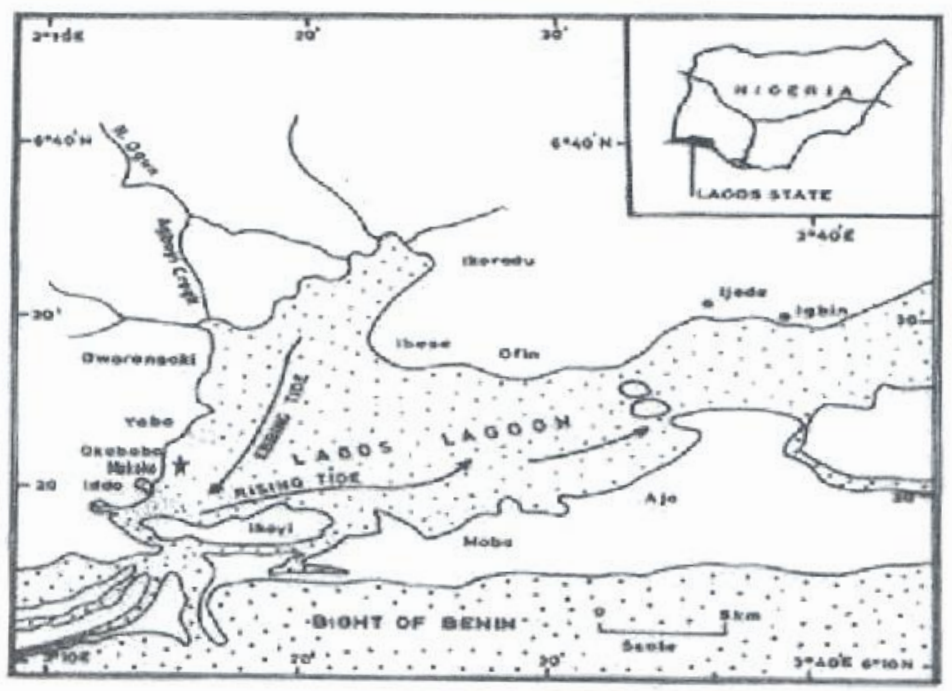

Fig. 1: Lagos lagoon showing sampling site

\section{Materials and Methods}

The crabs used for the project were collected from Lagos lagoon which is the largest brackish water body of the southern lagoon system in Nigeria (Webb, 1958) located between longitude $3^{\circ} 23^{\prime \prime} \mathrm{E}$ and $3^{\circ} 53^{\prime \prime}$ and latitude $6^{\circ} 26^{\prime \prime}$ and $6^{\circ} 37^{\prime \prime} \mathrm{N}$ (Fig. 1). The largest lagoon along the West African coast (tropical estuary), according to F.A.O. (1969), has a surface area of 208 square kilometers. The lagoon is an environment with an average depth of $1.5 \mathrm{~m}$ (Brown and Oyenekan, 1998) and opens all the year round (Onyema et al., 2003).

Collection of sample: The crabs used in this study were collected from Better-Life fish market of Makoko jetty between April and September, 2011. Collection of crabs was done randomly as they were being brought from the crab pots, which were set in the lagoon. The sampling was based on the presence of barnacles on any part of the crab, and they were immediately preserved in iced-cooler and later transferred into a deep-freezer in the laboratory prior to examination.

The crabs were removed from the freezer and allowed to thaw. Excess water was removed from the specimens using filter paper. The carapace length of the crab was measured to the nearest centimeters from the edge of the frontal region to the tip of the carapace backward using a simple measuring board, the carapace width was also measured using a vernier calliper. The total weight of the crabs was taken on a Sartorious Top Loading Balance (Model 1106) to the nearest tenth of a gram. The weight and length of the left and the right cheliped were measured to the nearest centimeters using a vernier caliper. Barnacles on the crab specimens were detached using a scalpel. Also, the location (specificity) and abundance of individual barnacle on crab was recorded. The relationship between the carapace length-frequency distributions was established and the cumulative worked out. For the study of the growth pattern, data for the carapace length-weight relationship and carapace width- weight relationship were compiled. The relationship between the carapace length and weight of the crab was expressed by the linear relationship equation:

$\log W=\log a+b \log L$ (Parsons, 1988) (Pauly, 1983; Parsons, 1988)

Where $\mathrm{W}=$ Weight of crabs in grams, $\mathrm{L}=$ Length of carapace in $\mathrm{cm}$, $\mathrm{a}=$ regression constant, $\mathrm{b}=$ regression coefficient.

- Condition factor $(\mathbf{K})$. The condition factor $(K)$ here indicates the state of general well being of the crab fouled with barnacles, was determined using the equation below:

$K=\frac{100 \mathrm{~W}}{L^{3}}$ (Gayanilo and Pauly, 1997)

Where $\mathrm{W}=$ weight of the crab in grams, $\mathrm{L}=$ carapace length in centimeters, $\mathrm{K}=$ Condition factor.

- Sex ratio. The ratio of male to female was determined based on the total number of male and female crabs that was studied. The chi-square $\left(\mathrm{X}^{2}\right)$ test on the sex ratio was calculated using the formula:

$$
X^{2}=\frac{(\text { Observed }- \text { Expected })^{2}}{\text { Expected }}
$$


This was carried out to test for any significant difference in the sex ratio of the crabs from the expected 1:1 ratio.

\section{Results}

A total of 810 specimens of $C$. amnicola fouled with Chelonibia patula were studied for length and width frequency distributions between April-September, 2011. Carapace length of $C$. annicola examined ranged from $3.8 \mathrm{~cm}-8.6 \mathrm{~cm}$ while carapace width ranged from $9.5 \mathrm{~cm}-15.4 \mathrm{~cm}$. The largest specimen of $C$. umnicola collected weighed $165.0 \mathrm{~g}$ while the smallest weighed $53.1 \mathrm{~g}$. The carapace length frequency polygon of C. amnicola showed distinct size groups. The size group: $6.5 \mathrm{~cm}-7.4 \mathrm{~cm}$ $(41.2 \%)$ was most abundant as shown in Fig. 2.

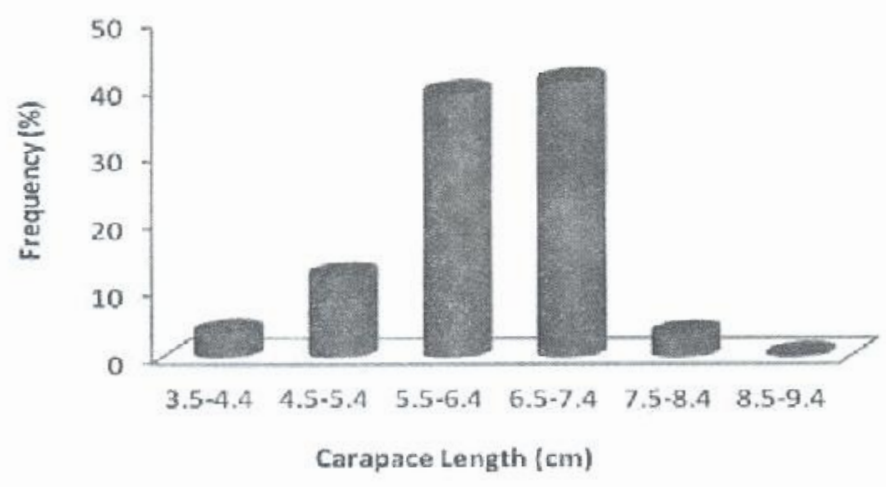

Fig. 2: Carapace length frequency distribution of $C$. amnicola with barnacles (April-September 2011).

The carapace width frequency of $C$. amnicola is shown in Fig. 3. The carapace width frequency polygon showed that the size group: $11.5-12.4 \mathrm{~cm}(47.9 \%)$ was most abundant.

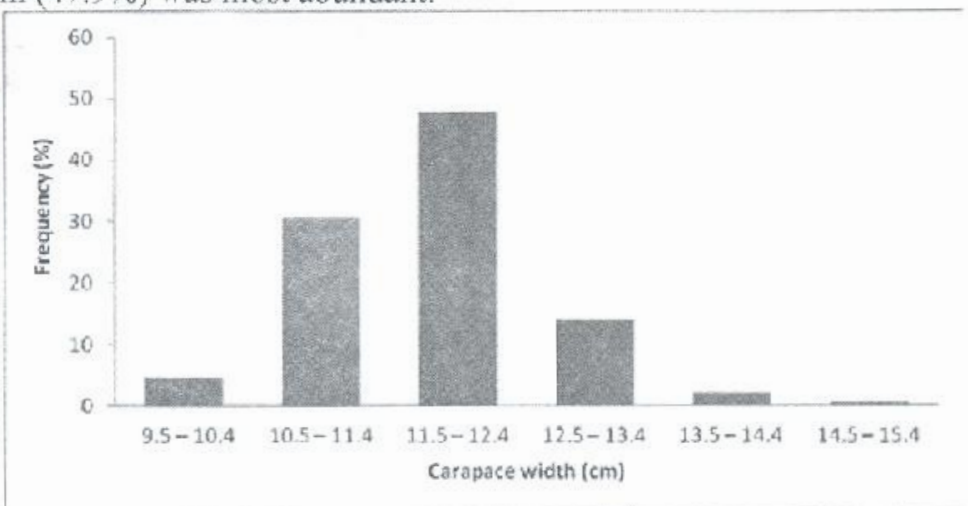

Fig. 3: Carapace width frequency distribution of Callinectes amnicola with barnacles.

The population was further divided into three size groups as shown in Table 1, as small crabs (CW:3.5 - 8.4cm), medium (CW:8.5 - 12.4) and large (CW:12.5 - 16.4). The medium size groups $(75.6 \%)$ of $C$. amnicola were predominant.

Table 1: Summary of carapace width frequency distribution (by size group) of C. amnicola from Lagos Lagoon (April-September 2011).

\begin{tabular}{lccc} 
Carapace width & & Number & \% frequency \\
Size Group & Range $(\mathrm{cm})$ & & \\
Small & $3.5-8.4$ & 6 & 0.7 \\
Medium & $8.5-12.4$ & 612 & 75.6 \\
Large & $12.5-16.4$ & 192 & 23.7 \\
Total & & 810 & 100 \\
\hline
\end{tabular}

Only twelve of the lagoon crabs examined was heavily fouled with barnacle. The crab with minimal number of attached barnacles was 2 while the maximum number was 136. Four different locations on the C. amnicola were fouled by C. patula: the carapace $(91.6 \%)$, the cheliped (3.7\%), the abdomen (4.4\%) and the fifth leg $(0.3 \%)$. Barnacle ectosymbionts were most abundant on carapace than any other target examined (Plates 1, 2 and 3). Figure 4 shows the summary of barnacle distribution and frequency on C. amnicola from Lagos lagoon (April-September, 2011) and it shows that the carapace of C. amnicola is mostly fouled by C. patula. 
Average diameter of the barnacle, C. patula attached to the lagoon crabs, C. amnicola ranged from $0.23 \mathrm{~cm}-1.85 \mathrm{~cm}$. The size distribution and abundance of barnacles showed that the frequency was independent on crab's width (Fig. 4 and 5 ).

On the average, large-sized crabs had as much barnacles attached to them as small- sized crabs.
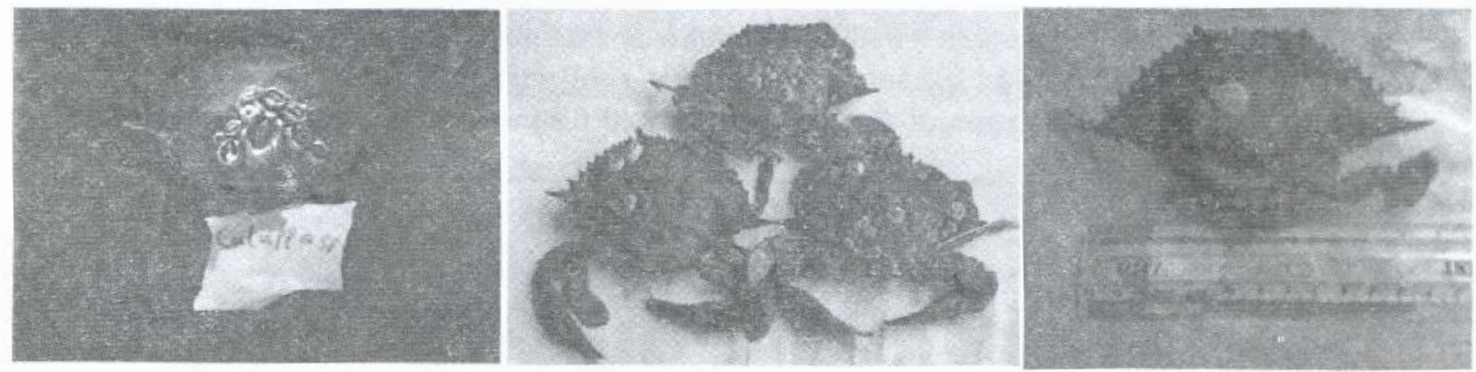

Plate 1: Dorsal view of $C$. amnicola with barnacles on the carapace.

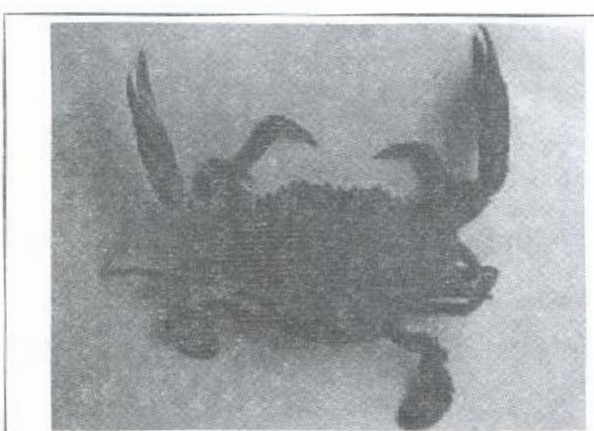

Plate 2: Ventral view of $C$. amnicola with barnacles attached to the abdomen.

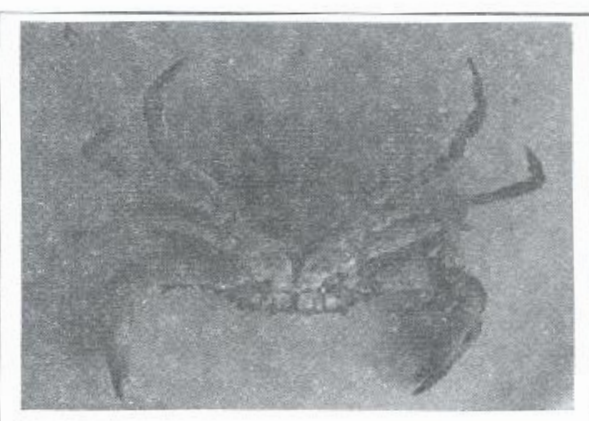

Plate 3: Dorsal view of $C$. amnicola with abundant barnacles attached on the carapace and chelipeds.

Table 2: Summary of barnacle distribution and frequency on $C$. amnicola from Lagos Lagoon.

\begin{tabular}{lcrcc}
\hline Location on crabs & $\begin{array}{c}\text { Number of crabs } \\
\text { attached }\end{array}$ & $\begin{array}{c}\text { Distribution of barnacle } \\
\text { CP }\end{array}$ & $\begin{array}{c}\text { Number of barnacles } \\
\text { attached }\end{array}$ & $\%$ \\
CH & 810 & 100 & 4746 & 91.6 \\
ABM & 112 & 14 & 194 & 3.7 \\
LG & 142 & 18 & 226 & 4.4 \\
Total & 22 & 3 & 18 & 0.3 \\
\hline
\end{tabular}

KEY: CP-Carapace, CH-Cheliped, ABM-Abdomen, LG-Sumiming le\&

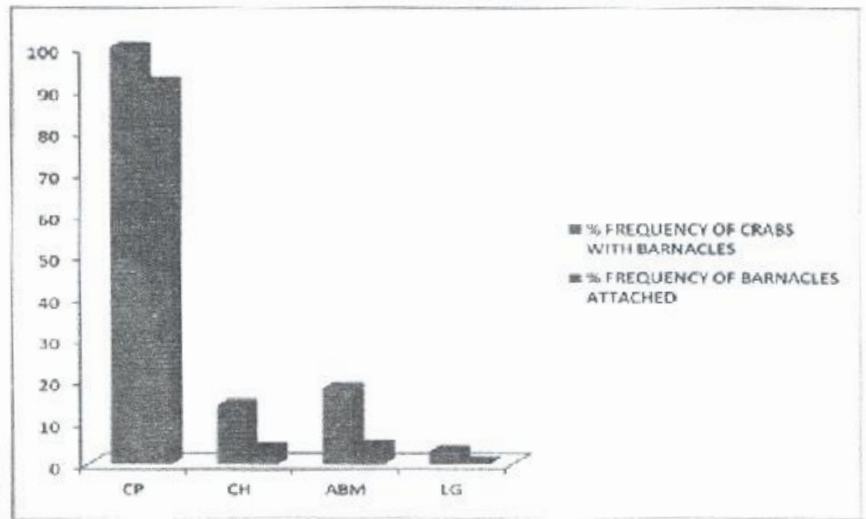

Fig. 4: Barnacle distribution and frequency on C. amnicola from Lagos Lagoon. 
Table 3: Summary of barnacle distribution on C. amnicola from Lagos Lagoon (April-September 2011) based on their carapace widths.

\begin{tabular}{lccc}
\hline Carapace width $(\mathrm{cm})$ & $\begin{array}{l}\text { Number of } \mathcal{C} . \\
\text { amnicola }\end{array}$ & $\begin{array}{l}\text { Number of } \\
\text { barnacles }\end{array}$ & $\begin{array}{l}\text { \% of } \\
\text { barnacles }\end{array}$ \\
\hline $9.5-10.4$ & 38 & 356 & 6.9 \\
$10.5-11.4$ & 246 & 1576 & 30.4 \\
$11.5-12.4$ & 388 & 2168 & 41.8 \\
$12.5-13.4$ & 114 & 902 & 17.4 \\
$13.5-14.4$ & 18 & 170 & 3.3 \\
$14.5-15.4$ & 6 & 12 & 0.2 \\
Total & 810 & 5184 & 100 \\
\hline
\end{tabular}

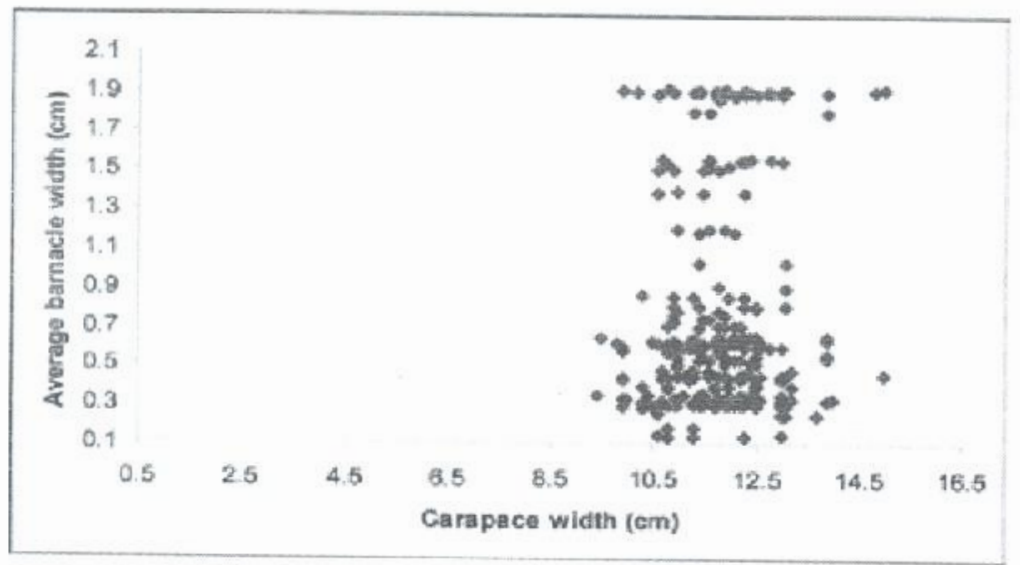

Fig. 5: Average width of barnacle and carapace width of $C$. amnicola from Lagos Lagoon.

- Growth pattern. The carapace length of $C$. amnicola ranged from $3.8 \mathrm{~cm}-8.6 \mathrm{~cm}$ while the carapace width ranged from $9.5 \mathrm{~cm}-15.4 \mathrm{~cm}$, the total weight ranged from $53.1 \mathrm{~g}-165.0 \mathrm{~g}$. The carapace length - total weight of $C$. amnicola was transformed into the logarithm form. The $\log$ length - $\log$ weight relationship showed a linear relationship between the length and weight of the crab. The scatter diagram showing log length and log weight relationship is illustrated in Fig. 6 below:

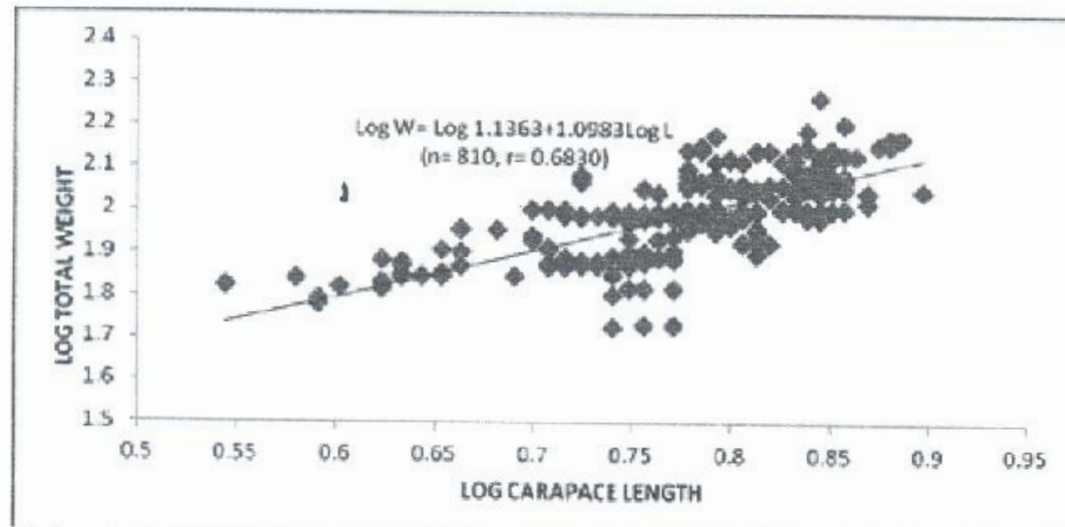

Fig. 6: Log length and log weight relationship of $C$. amnicola with barnacles.

The values of length - weight relationship for C. amnicola are given as follows:

$$
\log W=\frac{\log 1.1363+1.0983 \log L}{(n=810, r=0.6830)}
$$

The value of $b$ obtained for the crab was less than 3. This indicated that $C$. amnicola from Lagos lagoon exhibited a negative allometric growth. The correlated coefficient $\mathbf{r}$ was 0.68 for the crabs showing a low correlation between carapace length and total weight in the blue crabs fouled with barnacles.

- Condition factor $(\mathbf{K})$. The condition factor by size group of C.amnicola with barnacle attachment from Lagos lagoon is presented in Table 4. The $\mathrm{K}$ values ranged from 3.2 9.7 (combined sex). The highest $\mathrm{K}$-value was recorded for the size group (3.5-4.4). The value decreased with increase in carapace length of $C$. amnicola with a mean value of 5.4 
Table 4: Condition factor $(K)$ by size group of $C$. amnicola with barnacles from Lagos Lagoon (April-September, 2011).

\begin{tabular}{l|r|r|r|r|}
\hline CL Range $(\mathrm{cm})$ & N & CL $(\mathrm{cm})$ & Wi $(\mathrm{g})$ & K \\
\hline $3.5-4.4$ & 40 & 4.0 & 62.3 & 9.7 \\
\hline $4.5-5.4$ & 118 & 5.0 & 74.0 & 5.9 \\
\hline $5.5-6.4$ & 418 & 6.0 & 95.5 & 4.4 \\
$6.5-7.4$ & 214 & 7.0 & 125.4 & 3.7 \\
\hline $7.5-8.4$ & 20 & 8.0 & 165.0 & 3.2 \\
\hline TOTAL & 810 & & & 5.4 \\
\hline
\end{tabular}

KEY: $C L=$ Carapace Length $(\mathrm{cm}), W t=$ Total weight $(\mathrm{g}), N=$ Number, $K=$ Condition factor

- Sex Ratio. Out of the 810 specimens of the lagoon crabs with barnacle attachment studied, 10 were males while 800 crabs were females. The result of Chi-square test showed that the number of female lagoon crabs with barnacle attachment is significant $\left(X^{2}=770.50,1 \mathrm{df}\right.$. at $5 \%$ level) than the number of males. Thus, there is a significant difference between male and female crabs fouled with barnacles.

\section{Discussion}

The data collected on 810 species of $C$. amnicola showed that there were several size groups in the crabs' community sampled. The crabs with carapace length $6.5-7.4 \mathrm{~cm}(41.2 \%)$ was most abundant as shown in fig. 2 . The carapace width frequency polygon of $C$. amnicola also showed that the carapace width $11.5-12.4 \mathrm{~cm}(47.9 \%)$ was predominant. The population showed three main size groups as small crabs $0.7 \%(\mathrm{CW}: 3.5-8.4 \mathrm{~cm})$, medium $75.6 \%(\mathrm{CW}: 8.5-12.4 \mathrm{~cm})$ and large $23.7 \%(\mathrm{CW}: 12.5$

$16.4 \mathrm{~cm})$. The medium size groups being the most abundant and are mostly female $(98.8 \%)$ compared to the males $(1.2 \%)$. This supports the work of Marcus et al. (1997), that the prevalence and intensity of barnacles are dominantly controlled by the locomotory and migratory habits of the host since female crabs spend more time in deeper waters of higher salinity and stationary during molting and reproduction, thus they are more likely to be fouled by barnacle larvae. Of all the site of attachment, the specificity of attachment to the carapace of $C$. amnicola by $C$. patula was significant than any other part of the organism, this is in conformity with the results reported by Marcus et al. (1997) and Lawal-Are \& Daramola (2010). The spatial distribution of barnacles on the crab carapaces were controlled by the roughness of the surface of the carapace, availability and its conspicuousness on the lateral regions than medial. The settling barnacle larvae may prefer the dorsal surface because it is exposed to more light and probably more attractive biofilm (Crisp and Barnes, 1954).

Crabs were inhabited by barnacle populations having different densities and size frequencies. Average diameter of the barnacle, C. putula attached to the lagoon crabs, C. amnicala ranged from $0.23 \mathrm{~cm} 1.85 \mathrm{~cm}$. This was similar to the result reported by Afshin ct al. (2012), that the average diameter of the barnacle C. patula attached to the Portunus pelagicus crab ranged between $0.7 \mathrm{~cm}$ and $2.1 \mathrm{~cm}$. The size distribution and abundance of barnacles showed that the frequency was independent on crabs' width. This observation conformed to the results of Harold, (1983), that the barnacle Octolasmis millleri densities on Callinectes sapidus did not correlate with the crab size. He however opined that barnacles were significantly more abundant on the large gills of the crab.

The result of linear relationship between carapace length and wotal weight of the crab reflected an increase in weight with increasing length regardless of sex and age this was similar to the results obtained by Lawal-Are (1998). The lengthweight relationship exhibited a cluster pattern which indicated that the species were from the same age range within the lagoon. The carapace length-weight of the lagoon crabs with barnacles from Lagos Lagoon showed negative allometric growth showing that the carapace width grows horizontally instead of vertically with increase in weight also as reported by LawalAre, (2006), Guillory and Perret (1998). The correlated coefficient $r$ was 0.68 for the crabs showing a low correlation between carapace length and total weight in the blue crabs fouled by barnacles. Therefore, there was an indication that an increase in carapace width of the crabs fouled by barnacles gave a minimal increase in body weight.

The condition factor $(\mathrm{K})$ determining the habitat condition and overall well being of crab varied by size for the lagoon crabs from the Lagos Lagoon. A crab is said to be in a good habital condition when the value of $\mathrm{K}$ is high. The data on condition factor showed decrease in value with increase in carapace length with a mean value of 5.4. This indicated reduction in the capability to molt with age. Prager et al. (1990), observed that ecdysis becomes difficult as crabs grow old. The result of the sex ratio revealed that there is significant difference between male and female crabs fouled with barnacles, indicating that there were more females fouled than males. Despite the attachment of barnacles to the external area of the crabs, there was a steady growth of the crab, hence no indication of the attachment of barnacle to the exposed parts affecting the growth of the crab. 


\section{REFERENCES}

Afshin, A.B., Mehdi, N. and Mehdi, H. (2012): The distribution of Barnacle Epizoites, Chelonibita patula on Blue swimmer crab, Portunus pelagicus. Jozrnal of World Applied Sciences 20/2: 236-240.

Anderson, J. M., Cima, M. J. and Langer, R. (2003): Biocompatibility and biofouling of MEMS drug delivery devices. Biomaterials. 24/11: 1959-67.

Brown, C. A. and Oyenekan, J. A. (1998): Temporal variability in the structure of benthic macrofauna communities of the Lagos lagoon and harbour, Nigeria. Pol. Arch. Hydrobiol. 45/1: 45-54.

Carmona-Suarez, C. A. and Condc, J. E. (1996): Littoral brachyuran crabs (Crustacea: Decapoda) from Falcon, Venezuela, with biogeographical and ecological remarks. Rev. Bras. Biol. 56: 725-747.

Crisp, D. J. and Barncs, H. (1954): The orientation and distribution of barnacles at settlement with particular reference to surface contour. Journal of Animal Ecology, 23/4: $142-162$.

FAO (1969), Fisheries Survey in Western and Midwestern Region of Nigeria. UNDP/FAO Rome. SF: 74/NIR 6, 142pp.

Gayanilo, F. C. and. Pauly, D. (1997): FAO-ICLARM Stock Assessment Tools (FiSAT). FAO Computerized Information Series (Fisheries) No. 8, Rome, 262pp.

Guillory, V. and Perret, W. E. (1998): Management, history, status and trends in the Louisiana blue crab fishery. J. Shellfish Res. 17 (2): 413-424.

Harold, K. V. (1983): The distribution, size and reproduction of the pedunculate barnacle (Octolasmis mulleri) on the blue crab (Callinectes sapidius). F'ield Museum of Naturat History. Dept. of Zoology, Carlisle, Pennsylvania 68pp.

Hickman, C. P. (Jr.), Robert, L. S and Larson, A. (1996): Inlegrated Princuples of Zoology. 10th Ed., New York: McGraw-Hill. $901 \mathrm{pp.}$

Lawal-Are, A. O. (1998): Composition food and feeding habits and fecundity with particular reference to Badagry Lagoon crab (Callinectes amnicala). M.Sc. Thesis, University of Lagos, Nigeria. $86 \mathrm{pp}$.

, Kusemiju, K. (2000): Size composition, growth pattern and feeding habit of the blue crab (Callinectes amnicola) in the Badagry Lagoon, Nigeria. J. Sci. Res. Dev. 5:169-176.

(2006): The biology and culture potentials of the lagoon crab (Callinectes amnicala) from Badagry, Lagos and Lekki lagoons, Nigeria. PhD Thesis, 300pp.

Daramola, T. O. (2010): Biofouling of the barnacles (Cheionibia patuia) on two Portunid crabs (Callinectes amnicola) and (Portumus valitus) off Lagos Coast, Nigeria. European Journal of Scientific Reseurch 44(3): $520-526$.

Marcus, M. K. (Jr.), Jared, W. V., Williams, B. J. and Harold, K.V. (1997): Barnacle fouling of the blue crab (Callinectes sapidus) at Beaufort, North Carolina. Journal of Crusiacean Biology 17(3): 424439.

Onyema, I. C., Otudeko, O. G. and Nwankwo, D. I. (2003): The distribution and the composition of plankton around a sewage disposal site at Iddo, Nigeria. J. Sci. Res. Dev. 7: 1-24.

Panchal, C. B. (1984): Biofouling and corrosion studies at the seacoast test facility in Hawaii, CONF-840930-1, 6pp.

Parsons, R. (1998): Statistical Analysis: A Decision-Making Approach. 2nd cd. New York: Harper \& Row. $791 \mathrm{pp}$.

Pauly, D. (1983): Some simple methods for the assessment of tropical fish stocks. FAO Fish. Tech. Paper 234. 52pp.

Prager, M. H., McConaugha, J. R., Jones, C. M. and Geer, P. J. (1990): Fecundity of blue crab (Callinectes sapidus) in Chesapeake Bay: biological, statistical and management considerations. Bull. Mar: Sci. 46: 170-179.

Schneider, W. (1990): Field Guide to the Commercial Marine Resources of the Gulf of Guinea. FAO, Rome, 268pp.

Warner, G.F. (1982): The Biology of Crabs. London: Elek Science, 202pp.

Webb, J. E. (1958): The Ecology of Lagos Lagoon. The Lagoons of the Guinea Coast. London: Phil. Trans. Roy. Soc. 683 (241): 307-318.

Williams, A. B. (1984): Shrimps to Florida. Washington, DC: Smithsonian Institution Press, 550pp.

Zimmer, C. (2004): Parasite Rex. The Bizarre World of Nature's Most Dangerous Creatures. London: Free Press. 4:98-100. 